\title{
INVESTIGATION OF SURFACE PROPERTIES IN MANGANESE POWDER MIXED ELECTRICAL DISCHARGE MACHINING OF OHNS AND D2 DIE STEELS
}

\author{
S. Kumar ${ }^{1}$ and R. Singh ${ }^{2}$ \\ ${ }^{1}$ Faculty of Mechanical Engineering, Punjab Engineering College \\ Chandigarh, 160012, India \\ ${ }^{2}$ Faculty of Production Engineering, Guru Nanak Dev Engineering College \\ Ludhiana, 141006, India \\ Tel.: +919872257575, Fax: +911612502700 \\ E-mail: rupindersingh78@yahoo.com
}

\begin{abstract}
The electrical discharge machining (EDM) process is used for generating accurate internal profiles in hardened materials. An powder additive in the hydrocarbon dielectric affects the energy distribution and sparking efficiency, and consequently the surface finish and micro-hardness. In this paper the Taguchi approach has been used to optimize and compare the surface properties in manganese powder-mixed EDM of oil-hardening non-shrinkable (OHNS) and high-carbon high-chromium (D2) die steels. The results of the study show an improvement of $73 \%$ and $71.6 \%$ in the micro-hardness of OHNS and D2 die steels, respectively. The machining parameters for the best value of microhardness are found to be the same for both work materials. A scanning electron microscopy and X-ray diffraction analysis of the machined surfaces show a transfer of manganese and carbon from the plasma channel in the form of manganese carbide. The chemical composition of the machined surface has been further checked on an optical emission spectrometer to verify and quantify the results.
\end{abstract}

Keywords: Electrical discharge machining, Manganese powder, OHNS die steel, D2 die steel, Powder-mixed dielectric, Taguchi design

\section{INTRODUCTION}

In the electrical discharge machining (EDM) process, two metal electrodes, one being a tool of a pre-determined shape, and the other being the workpiece, are immersed in a dielectric liquid which is generally kerosene or any other hydrocarbon oil. A series of voltage pulses, usually of rectangular form, with magnitude about $100 \mathrm{~V}$ and frequency of the order of 200-5000 Hz, is applied between the two electrodes (Mishra, 2005). The entire cycle time is usually a few micro-seconds (Fuller, 2000; Jain, 2004). However, the temperature of the area under the spark is very high. The process can be controlled in such a way that substantially more material is removed from the workpiece than the tool-electrode (Shankar and Krishnan, 1979). The high frequencies at which the voltage pulses are supplied, together with the forward movement of the tool-electrode towards the workpiece by means of a servo-mechanism, enables the sparking action to be eventually achieved over the entire area of the electrodes in contact (Ho and Newman, 2003). Since metal removal is realized by sparks and not mechanical action, the rate of machining is not limited by the hardness of the workpiece. These attractive features of 
EDM have led to its widespread industrial use, particularly in the manufacture of dies and moulds (Altan et al., 1993) where the material can be machined in the hardened state and distortions resulting from heat treatment processes are eliminated.

A number of phenomena observed during the EDM process make it a high potential technology for application in the field of surface modification. Each spark generates a temperature of the order of 8,000 to $12,000{ }^{0} \mathrm{C}$ and creates a plasma channel, causing fusion or partial vaporization of the workpiece, tool electrode and the dielectric fluid at the point of discharge (Kuneida et al., 2005). When the plasma channel collapses at the end of pulse on-time, the flowing dielectric cools the surfaces and carries away most of the vaporized material (Zolotykh, 1995). However, some of the constituents of the plasma channel are deposited back on the workpiece and the tool electrode. Many research works have reported the presence of the constituents of tool electrode in the machined workpiece surface and vice-versa (Aspinwall et al., 2003). Pyrolysis of the hydrocarbon dielectric contributes carbon to the plasma channel and aids the process of material deposition (Lahiri et al., 1981). As the dissolution of the electrode takes place during the process, the constituents of the electrode material may be deposited on the machined surface by varying the process parameters towards the end of the machining cycle for specific surface modifications (Kumar et al., 2009). Suitable alloying elements may be added to the electrode bodies or suspended in the dielectric in the form of fine metal powders and they may get deposited on the machined surface either in free form or as carbides by combining with carbon from the breakdown of the dielectric (Tzeng and Lee, 2001). Suspended powders also influence the sparking pattern and machining efficiency (Jeswani, 1981). Conductive powders enlarge the gap distance and improve the surface finish by reducing spark energy and dispersing the discharges more randomly throughout the surface (Rehbein et al., 2004): the thickness of the recast layer is smaller and micro-cracks are reduced. Consequently, the corrosion resistance of the machined surface is substantially improved.

\section{LITERATURE REVIEW}

In the case of dies, punches and other press tools, it is desirable to introduce suitable alloying elements and their compounds in the machined surfaces only and not in the base material due to the following very important reasons:

- The contribution of the alloying elements in improving mechanical and physical properties is desired at the interacting surfaces only and material going into the rest of the component body adds a substantial cost to it.

- The presence of these alloying elements significantly affects the heat treatment behaviour of die steels. For example, most carbide forming elements $(\mathrm{Mn}, \mathrm{Cr}$, $\mathrm{W}, \mathrm{Mo}, \mathrm{V}$ and $\mathrm{Ti}$ ) impede carbon diffusion in austenite and make the process of transformation of pearlite into austenite slower (Prabhudev, 2000). They also increase the stability of supercooled austenite in the pearlitic region to a much greater degree, which results in a large amount of retained austenite instead of the desirable martensite (Lakhtin, 1983). Hence, it becomes imperative that alloying elements are introduced after the heat treatment cycle.

- It may not be metallurgically feasible to add some of the elements (such as refractory metals) in the molten state to the whole liquid material. 
Two types of surface modification methods commonly employed for dies and moulds are ion implantation and laser surface processing (Kalpakjian and Schmid, 2001). However, both these processes are characterized by poor surface finish and require final machining on EDM. Another hindrance is the enormous cost of the equipment (Galerie et al., 1989). Since EDM is already being used extensively for the machining of press tools, dies and punches, if surface modification can be incorporated into the EDM process itself, it will bring substantial economic benefits to the industry. For example, oil-hardening non-shrinkable (OHNS) die steel has medium toughness and moderate wear resistance (ASM, 1995). These characteristics can be improved by the addition of carbon, manganese, chromium and vanadium to the machined surface. Manganese improves strength and hardness, but to a lesser degree than carbon, and is most effective in high carbon steels. It increases the hardenability of alloy steels and its carbide forming ability is greater than that of ferrite but less than that of chromium (Pollack, 1988). It also improves the hot working properties of tool and die steels. Besides this, some elements have a strong influence on the properties of tool steels when they are used in combination with some other specific elements. When manganese is added to a tool steel containing chromium, silicon and molybdenum; it increases the strength, toughness and hardness. The effect of manganese is then greater than that of chromium (Avner, 1997).

Roethel and Garbajs (1976) observed that the properties of the surfaces depend on the properties of the alloys which are formed in the surface layers due to the diffusion of tool electrodes and breakdown of the dielectric. Many researchers have carried out investigations into the phenomenon of material transfer from composite electrodes but only a limited literature is available on the use of powder-mixed dielectric for surface modification. Uno et al. (2001) conducted experiments on aluminum bronze work material with nickel powder mixed in the dielectric and obtained a surface of high wear resistance and good surface finish as compared to conventional EDM due to the transfer of nickel. Furutani (2001) used titanium powder in kerosene dielectric and obtained titanium carbide layer of hardness $1600 \mathrm{HV}$ on carbon steel with a negatively polarized copper electrode, $3 \mathrm{amp}$ peak current and $2 \mu \mathrm{sec}$ pulse duration. Both titanium and titanium carbide were found in the X-ray diffraction analysis of the machined surface and it was concluded that carbon came from the breakdown of the dielectric. A deposition method for a solid lubricant layer of molybdenum disulphide by suspending its powder in the dielectric to produce parts for ultra high vacuum applications (such as space environment) has been proposed by Furutani and Shimizu (2003). The process is not without its drawbacks, which include the difficulty in ensuring that the powder is held in suspension. This is easier with more viscous dielectrics but at the cost of reduced flushing efficiency (Aspinwall et al., 2003). To address the problem of powder settling, $\mathrm{Wu}$ et al. (2005) added a surfactant with aluminum powder in the dielectric and observed a more apparent discharge distribution effect which resulted in a surface roughness $\left(\mathrm{R}_{\mathrm{a}}\right.$ value) of less than $0.2 \mu \mathrm{m}$. By adding urea to distilled water as the dielectric medium for machining titanium, Yan et al. (2005) obtained TiN on the work surface which exhibited improved friction and wear characteristics. It has been shown that there is a great influence of the work material and powder properties on the response parameters such as material removal rate (MRR), tool wear rate (TWR) and surface roughness; besides the appropriate settings of electrode polarity and pulse parameters. The available literature establishes that low peak current, shorter pulse ontime and negative polarity of the tool electrode favour the phenomenon of surface 
modification by EDM process. However, the impact of variation in pulse off-time as an independent parameter has not been investigated till date.

\section{EXPERIMENTAL DETAILS}

This research work attempts to carry out surface modification of OHNS (type 'O2') and 'D2' die steels by material transfer from manganese powder suspended in the dielectric medium using the EDM process. The chemical composition of the work materials was measured on an optical emission spectrometer and is given in Table 1. OHNS and D2 die steels contain $0.82 \%$ and $1.57 \%$ carbon, respectively. The high carbon content makes possible the formation of martensite of high hardness, and the alloying elements provide sufficient hardenability to make possible hardening of sections of reasonable size by oil quenching (ASM, 1995). Hardening is done by oil quenching from austenitizing temperatures, followed by two cycles of tempering to remove internal stresses and maximize the transformation of austenite to martensite. These die steels have very low susceptibility to distortion and cracking (Roberts and Cary, 1980). The microstructure of hardened and tempered OHNS and D2 die steels is shown in Figures 1 and 2, respectively. In the scanning electron micrograph of OHNS die steel, spheroidal cementite phase appears in the matrix of tempered martensite. In the micrograph of D2 high-carbon high-chromium die steel (Figure 2), large un-dissolved carbides can be seen in a tempered martensite matrix.

Table 1: Chemical composition of OHNS die steel

\begin{tabular}{lcc}
\hline Element & \multicolumn{2}{c}{ Composition (\% of wt.) } \\
\cline { 2 - 3 } & OHNS die steel & D2 die steel \\
\hline Carbon & 0.82 & 0.82 \\
Silicon & 0.18 & 0.18 \\
Manganese & 0.52 & 0.52 \\
Chromium & 0.49 & 0.49 \\
Tungsten & - & - \\
Vanadium & 0.19 & 0.19 \\
Molybdenum & 0.13 & 0.13 \\
Nickel & 0.05 & 0.05 \\
Iron & Balance & Balance \\
\hline
\end{tabular}

The original micro-hardness of the work materials was measured at six different places and the average value was found to be $607 \mathrm{HV}$ and $652 \mathrm{HV}$ (Vickers hardness number) respectively. Machining of the workpieces was carried out using negative polarity of the tool electrode and kerosene dielectric with side flushing for all the experiments. The time for each machining cut was fixed at 10 minutes. The machining parameters used for experimentation have been summarized in Table 2. 


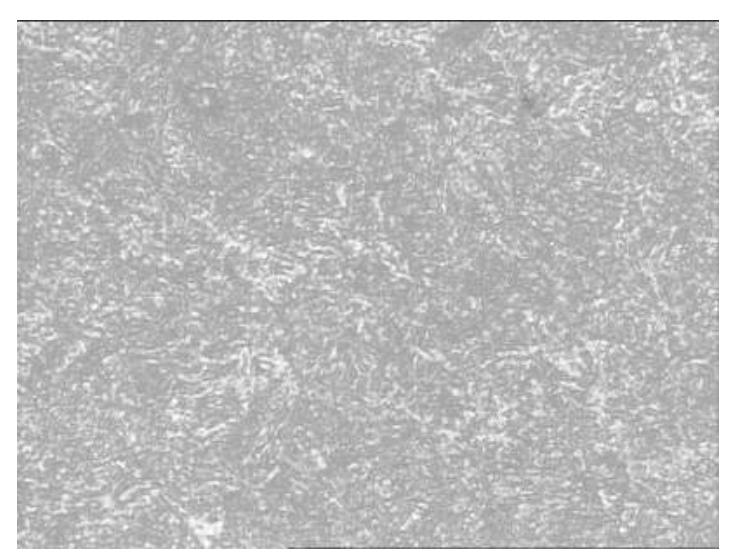

(a) $400 \mathrm{X}$

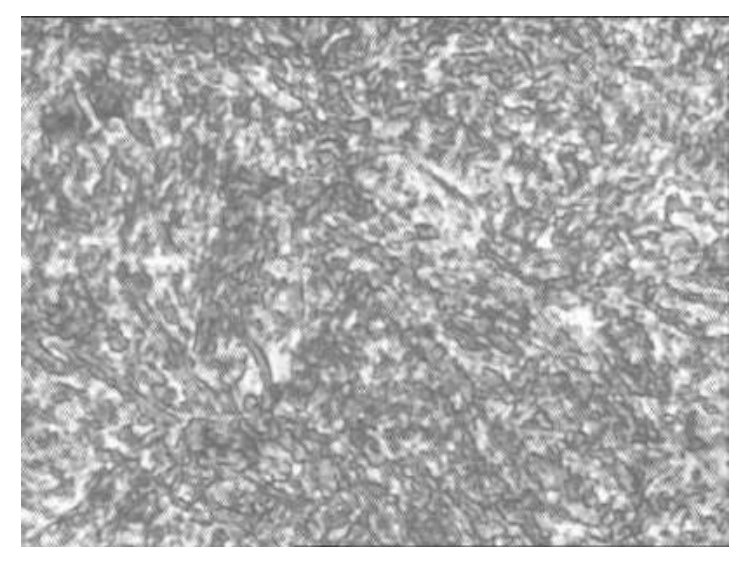

(b) $1000 \mathrm{X}$

Figure 1. SEM micrograph of the original microstructure of OHNS die steel

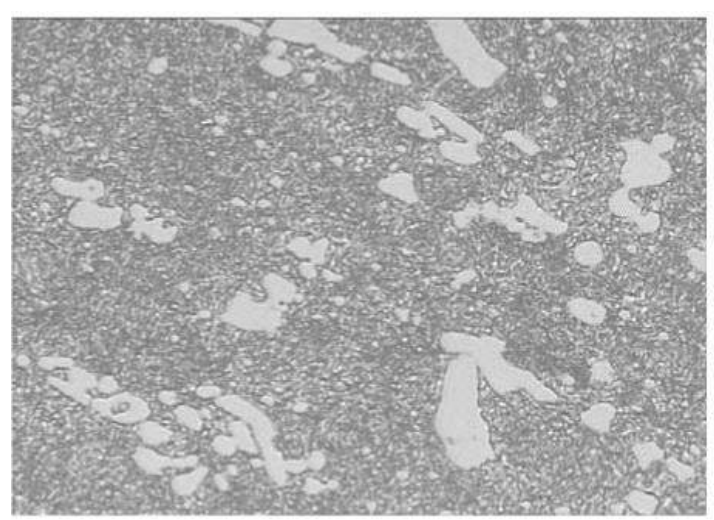

(a) $400 \mathrm{X}$

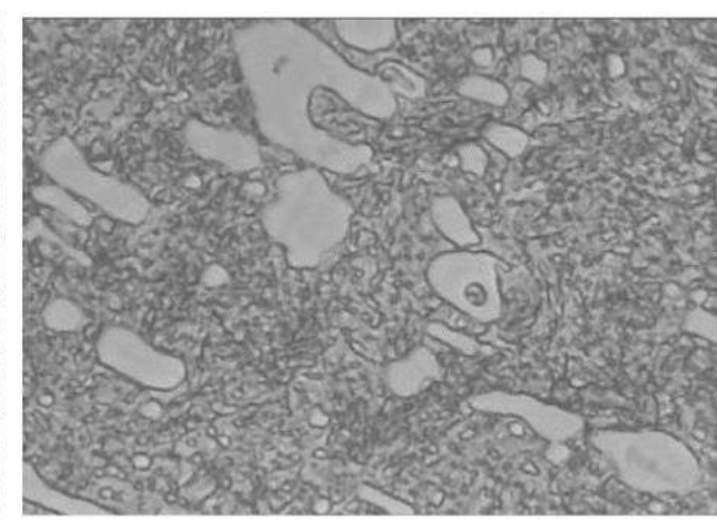

(b) $1000 \mathrm{X}$

Figure 2. SEM micrograph of the original microstructure of D2 die steel

Table 2. Machining Parameters

\begin{tabular}{ll}
\hline Parameters & \multicolumn{1}{c}{ Description and value } \\
\hline Sparking Voltage & $135 \pm 5 \%$ Volts \\
Discharge Current & $2,4,6 \mathrm{Amps}$ \\
Pulse on-time & $5,10,20 \mu \mathrm{sec}$ \\
Pulse off-time & $38,57,85 \mu \mathrm{sec}$ \\
Servo Control & Electro-mechanical \\
Polarity & Reverse (electrode negative) \\
Dielectric & Commercial grade Kerosene \\
Flushing & Side flushing with pressure \\
Machining Time & 10 minutes for each cut \\
Workpiece material & OHNS die steel (hardened and \\
& tempered) \\
Tool Electrode & Copper \\
Powder Concentration & $15 \mathrm{~g} /$ liter \\
\hline
\end{tabular}


For the manganese powder-mixed dielectric, a small tank made of thin mild steel sheet was placed in the main machining tank to isolate it from the filtering system of the machine. This tank was provided with a stirrer to keep the powder suspended uniformly in the dielectric throughout the machining cycle. For comparison purposes, the work material was also machined with the same process parameters but without any powder suspended in the dielectric medium. The best value of micro-hardness under these normal conditions was found to be $683 \mathrm{HV}$ and $748 \mathrm{HV}$ respectively. The XRD pattern of the surface of OHNS die steel machined without any powder shows the presence of cementite $\left(\mathrm{Fe}_{3} \mathrm{C}\right)$, ferrite $(\mathrm{Fe}-\mathrm{C})$ and some traces of copper (Figure 3).

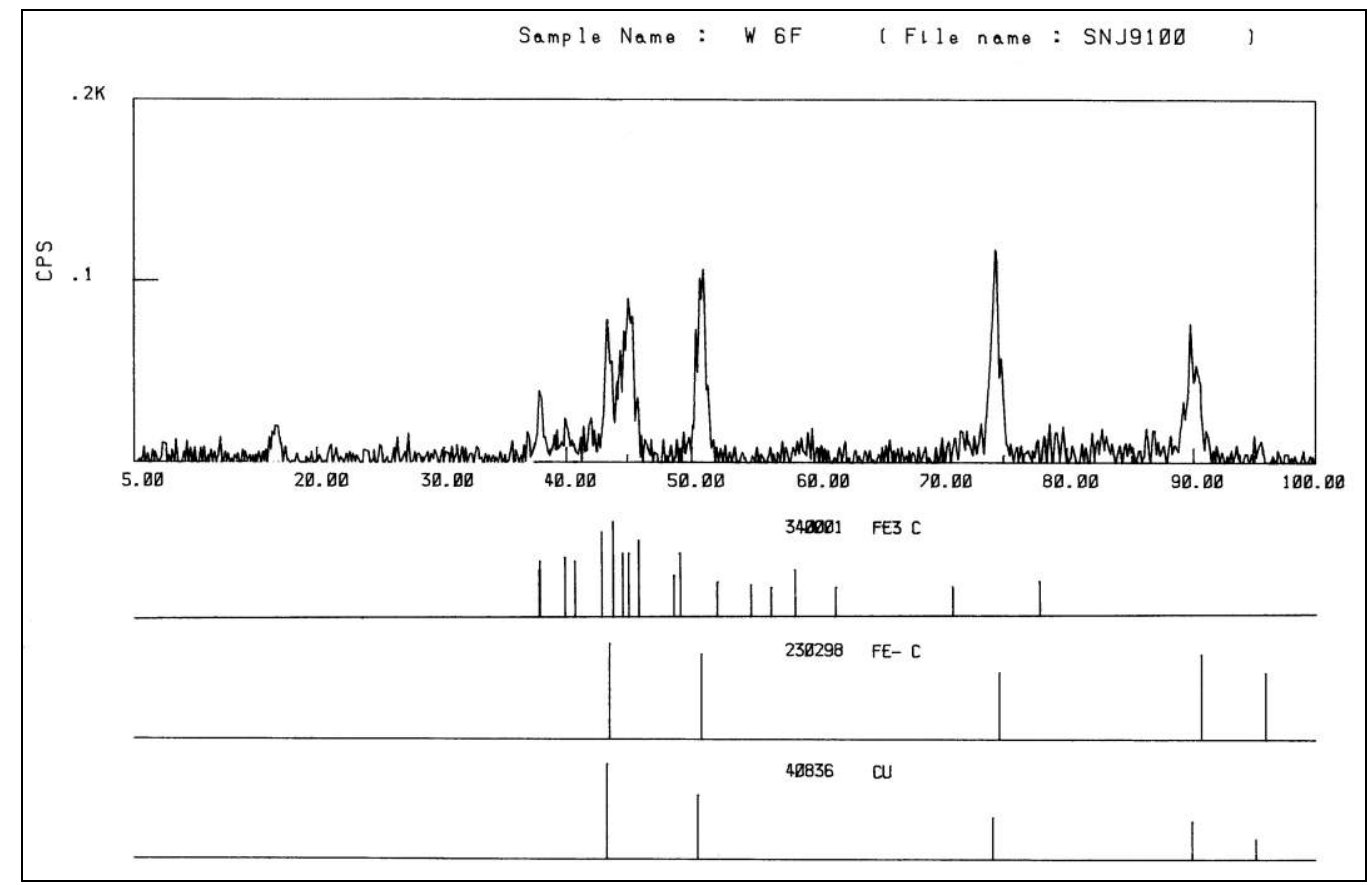

Figure 3. XRD pattern of OHNS die steel after machining with copper electrode (at $\mathrm{I}_{\mathrm{p}}=6 \mathrm{amp}, \mathrm{P}_{\text {on }}=5 \mu \mathrm{sec}$ and $\mathrm{P}_{\text {off }}=85 \mu \mathrm{sec}$ )

As the machining conditions used for the experiments favour high tool wear, this copper has come from the dissolution of the electrode. Copper-like nickel, silicon and aluminum - does not form carbides in steel and is found as a solid solution with iron. The effect of copper in improving the mechanical properties of ferrite phase is only marginal, but in any case, its presence is not detrimental to the properties. Hence, no attempt has been made in this research work to eliminate copper from the workpiece surface. The corresponding microstructure of this surface is shown in Figure 4 in which the typical craters formed after normal EDM can be distinctly seen. 


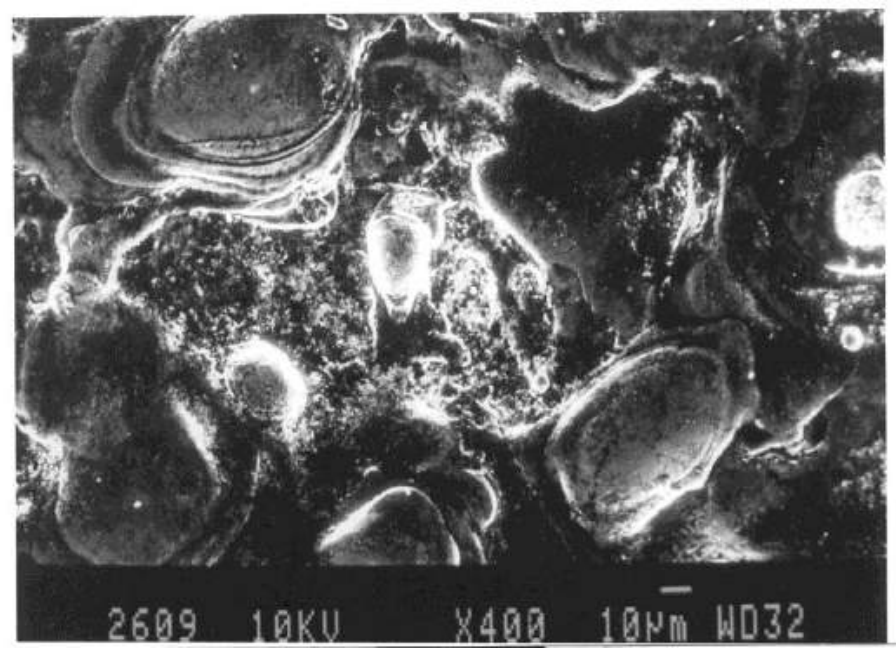

Figure 4. SEM micrograph of OHNS die steel after machining with copper electrode (at $\mathrm{I}_{\mathrm{p}}=6 \mathrm{amp}, \mathrm{P}_{\text {on }}=5 \mu \mathrm{sec}$ and $\mathrm{P}_{\text {off }}=85 \mu \mathrm{sec}$ )

\section{Experimental Design}

For this experimental work, three input process parameters (also called factors), namely, peak current, pulse on-time and pulse off-time, were chosen based on extensive literature survey and pilot experimentation. Three levels of each parameter were taken because the non-linear behaviour of a process parameter can only be studied if more than two levels are used (Montgomery, 2005). The degrees of freedom (DOF) of a three level parameter is 2 (number of levels-1), hence the total DOF for the experiment is 6. Out of the standard orthogonal arrays available in Taguchi design, the L9 orthogonal array has 8 degrees of freedom and it can accommodate three levels of up to four parameters, so it was selected for this work (Bagchi, 1993). The fourth column of the array has been left blank. The orthogonality of an array is not lost if one or more columns are not used (Phadke, 1989). Taguchi recommends that study of interaction should be avoided, if possible, by proper assignment of the factors. Amongst the parameters of this design, it is well known from previous research work that in EDM, the effects of variation in peak current and pulse on-time on the output parameters are independent of each other: there is no interaction between them. Hence, they have been assigned to columns 1 and 2. The third factor, pulse off-time, has been assigned to column 3. Each row of the orthogonal array represents the set of values of input process parameters with which a particular experiment is to be conducted. Thus, a total of nine experiments are required for one phase of a study (Ross, 1988). Accordingly, after constructing the control log, each set of nine experiments was repeated three times at random for both the work materials. The input process parameters and their levels used for the experimentation have been listed in Table 3 .

Table 3. Input process parameters and their levels

\begin{tabular}{lccc}
\hline \multicolumn{1}{c}{ Parameter } & \multicolumn{3}{c}{ Levels } \\
\cline { 2 - 4 } & L1 & L2 & L3 \\
\hline Peak current $($ Amperes $)$ & 2 & 4 & 6 \\
Pulse on-time $(\mu \mathrm{sec})$ & 5 & 10 & 20 \\
Pulse off-time $\mu \mathrm{sec})$ & 38 & 57 & 85 \\
\hline
\end{tabular}


The most important output process parameter for dies and press tools is microhardness of the working surface as it directly influences the quality and life of the tools; hence it was selected as the response characteristic for this experimental work. Microhardness tests were carried out using a load of $9.807 \mathrm{~N}$ for a duration time of 20 seconds on the bottom surface of the machined cavity. For each sample, measurement was done at three places and average values were taken. Analysis of variance (ANOVA) of the data was done to find out the significance and percentage contribution of each of the three factors towards improving micro-hardness. Surface roughness $\left(R_{a}\right.$ value) measurements were also done on all the samples. The machined surfaces showing the maximum improvement in micro-hardness were further subjected to X-ray diffraction (XRD) analysis to find out the presence of additional elements and the various phases; scanning electron microscopy (SEM) to analyse the microstructure; and composition testing by an optical emission spectrometer for quantitative analysis of the changes in constituents of the machined surface.

\section{RESULTS AND DISCUSSION}

A total of 27 samples (for each work material) were obtained after repeating each set of nine experiments three times. As the aim of the experimentation was to maximize the value of micro-hardness, this is a higher-the-better type of response characteristic, for which the signal-to-noise ratio ( $S / N$ ratio, denoted by ' $\eta$ ') was calculated for higher the better type (HB) as:

$$
\eta=(S / N)_{H B}=-10 \log \left[\frac{1}{R} \sum_{j=1}^{R}\left(\frac{1}{y_{j}^{2}}\right)\right]
$$

where $y_{j}=$ observed value of the response characteristic

$R=$ number of repetitions

The observed values of micro-hardness and the calculated values of their $\mathrm{S} / \mathrm{N}$ ratios for OHNS and D2 die steel are shown in Tables 4 and 5, respectively. The average surface roughness values for each set of machining conditions are also given in these tables. The average values of micro-hardness and the corresponding $\mathrm{S} / \mathrm{N}$ ratios at levels 1, 2 and 3 of the three input process parameters were then calculated to find out the factor effects. These factor effects have been shown in Figures 4 and 5 for OHNS and $\mathrm{D} 2$ die steels, respectively.

Taguchi suggests two different routes to carry out the complete analysis of the experimental data. In the first approach, the results of a single run or the average of repetitive runs are processed through main effect and ANOVA analysis of the raw data is carried out. The second approach, which Taguchi strongly recommends, is to use signal-to-noise ( $\mathrm{S} / \mathrm{N})$ ratios for the same steps in the analysis (Phadke, 1989). It is treated as a response parameter (a transform of the raw data) of the experiment. Based on this recommendation, the second approach was chosen for the analysis of the data in this work. The results of ANOVA of the S/N data are given in Tables 6 and 7 for OHNS and D2. The $F$-ratio is a statistical parameter that determines whether a factor is significant for the response characteristic or not. If the calculated value of the $F$-ratio from the experimental data is more than the specified value of the $F$-ratio for a given 
level of confidence (available from statistical tables), the factor is significant, and otherwise it is not.

Table 4. Observed values of micro-hardness for OHNS die steel and their $\mathrm{S} / \mathrm{N}$ ratios

\begin{tabular}{|c|c|c|c|c|c|c|c|c|}
\hline \multirow[t]{2}{*}{$\begin{array}{l}\text { Expt. } \\
\text { No. }\end{array}$} & \multicolumn{3}{|c|}{ Factor Values } & \multicolumn{3}{|c|}{$\begin{array}{l}\text { Micro-hardness } \\
\text { values }\end{array}$} & \multirow{2}{*}{$\begin{array}{l}\mathrm{S} / \mathrm{N} \\
\text { ratio } \\
(\eta)\end{array}$} & \multirow{2}{*}{$\begin{array}{l}\text { Average } \\
\text { surface } \\
\text { roughness, } \\
\mathbf{R}_{\mathbf{a}}(\mu \mathrm{m})\end{array}$} \\
\hline & $\begin{array}{l}\text { Peak } \\
\text { current } \\
\text { (amp) }\end{array}$ & $\begin{array}{l}\text { Pulse } \\
\text { on-time } \\
\text { ( } \mu \text { sec) }\end{array}$ & $\begin{array}{l}\text { Pulse } \\
\text { off-time } \\
\text { ( } \mu \text { sec) }\end{array}$ & $\begin{array}{l}\text { R1 } \\
\text { (HV) }\end{array}$ & $\begin{array}{l}\text { R2 } \\
\text { (HV) }\end{array}$ & $\begin{array}{l}\text { R3 } \\
\text { (HV) }\end{array}$ & & \\
\hline 1 & 2 & 5 & 38 & 843 & 851 & 865 & 58.618 & 3.31 \\
\hline 2 & 2 & 10 & 57 & 820 & 783 & 794 & 58.046 & 3.72 \\
\hline 3 & 2 & 20 & 85 & 837 & 861 & 848 & 58.573 & 4.60 \\
\hline 4 & 4 & 5 & 57 & 1018 & 1029 & 1036 & 60.236 & 5.68 \\
\hline 5 & 4 & 10 & 85 & 996 & 1007 & 983 & 59.958 & 6.60 \\
\hline 6 & 4 & 20 & 38 & 978 & 962 & 971 & 59.738 & 6.52 \\
\hline 7 & 6 & 5 & 85 & 988 & 1011 & 995 & 59.981 & 6.34 \\
\hline 8 & 6 & 10 & 38 & 914 & 905 & 883 & 59.089 & 6.02 \\
\hline 9 & 6 & 20 & 57 & 939 & 912 & 921 & 59.312 & 6.83 \\
\hline \multicolumn{4}{|c|}{ Overall Mean } & \multicolumn{3}{|c|}{924.07} & 59.283 & 5.51 \\
\hline
\end{tabular}

Table 5. Observed values of micro-hardness for $\mathrm{D} 2$ die steel and their $\mathrm{S} / \mathrm{N}$ ratios

\begin{tabular}{|c|c|c|c|c|c|c|c|c|}
\hline \multirow[t]{2}{*}{$\begin{array}{l}\text { Expt. } \\
\text { No. }\end{array}$} & \multicolumn{3}{|c|}{ Factor Values } & \multicolumn{3}{|c|}{$\begin{array}{l}\text { Micro-hardness } \\
\text { values }\end{array}$} & \multirow{2}{*}{$\begin{array}{l}\mathrm{S} / \mathrm{N} \\
\text { ratio } \\
(\eta)\end{array}$} & \multirow{2}{*}{$\begin{array}{l}\text { Average } \\
\text { surface } \\
\text { roughness, } \\
\mathbf{R}_{\mathbf{a}}(\mu \mathrm{m})\end{array}$} \\
\hline & $\begin{array}{l}\text { Peak } \\
\text { current } \\
\text { (amp) }\end{array}$ & $\begin{array}{l}\text { Pulse } \\
\text { on-time } \\
\text { (usec) }\end{array}$ & $\begin{array}{l}\text { Pulse } \\
\text { off-time } \\
\text { (usec) }\end{array}$ & $\begin{array}{l}\text { R1 } \\
\text { (HV) }\end{array}$ & $\begin{array}{l}\text { R2 } \\
\text { (HV) }\end{array}$ & $\begin{array}{l}\text { R3 } \\
\text { (HV) }\end{array}$ & & \\
\hline 1 & 2 & 5 & 38 & 953 & 978 & 962 & 59.683 & 4.47 \\
\hline 2 & 2 & 10 & 57 & 905 & 896 & 883 & 59.032 & 4.50 \\
\hline 3 & 2 & 20 & 85 & 917 & 938 & 921 & 59.325 & 5.53 \\
\hline 4 & 4 & 5 & 57 & 1064 & 1081 & 1109 & 60.702 & 6.09 \\
\hline 5 & 4 & 10 & 85 & 1058 & 1019 & 1046 & 60.261 & 7.28 \\
\hline 6 & 4 & 20 & 38 & 1027 & 1019 & 1046 & 60.261 & 7.57 \\
\hline 7 & 6 & 5 & 85 & 1042 & 1051 & 1072 & 60.463 & 7.65 \\
\hline 8 & 6 & 10 & 38 & 980 & 963 & 994 & 59.756 & 7.78 \\
\hline 9 & 6 & 20 & 57 & 956 & 945 & 917 & 59.452 & 8.04 \\
\hline \multicolumn{4}{|c|}{ Overall Mean } & & 992.41 & & 59.914 & 6.66 \\
\hline
\end{tabular}

R1, R2 and R3 represent the three repetitions. 


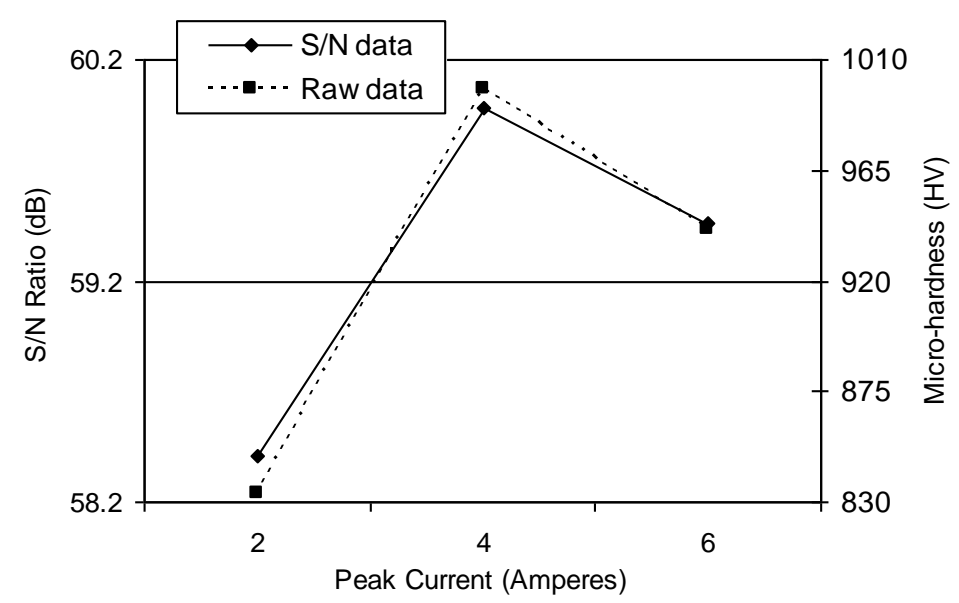

(a)

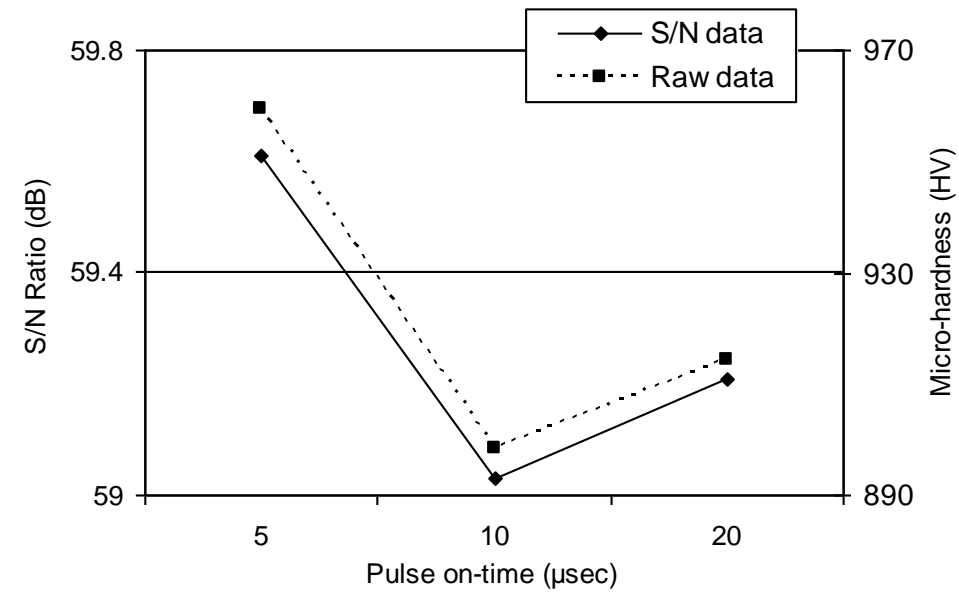

(b)

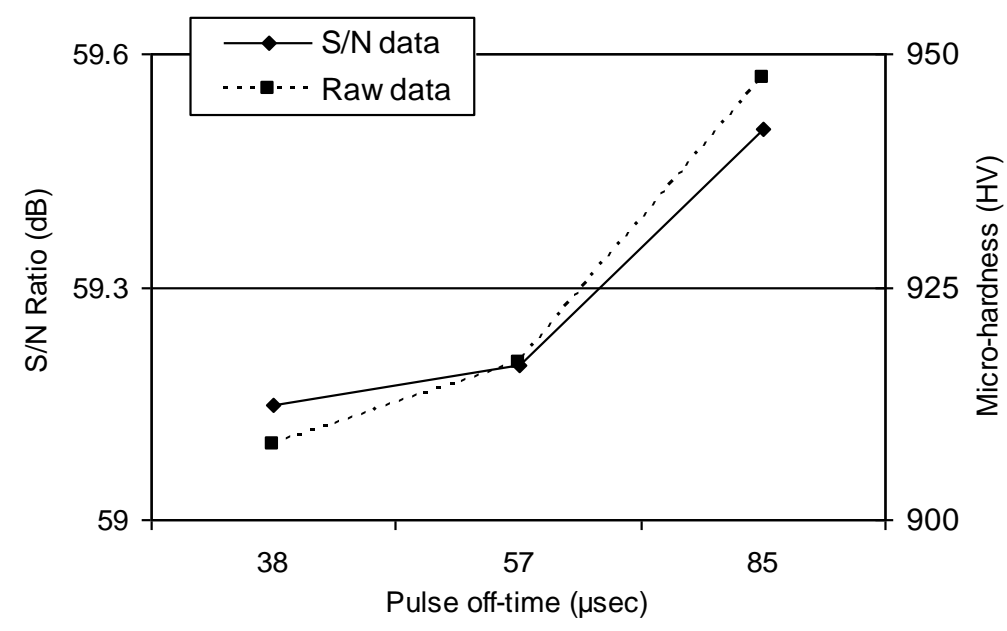

(c)

Figure 5. Effect of (a) Peak current (b) Pulse on-time and (c) Pulse off-time against micro-hardness and its $\mathrm{S} / \mathrm{N}$ ratio, for OHNS die steel 


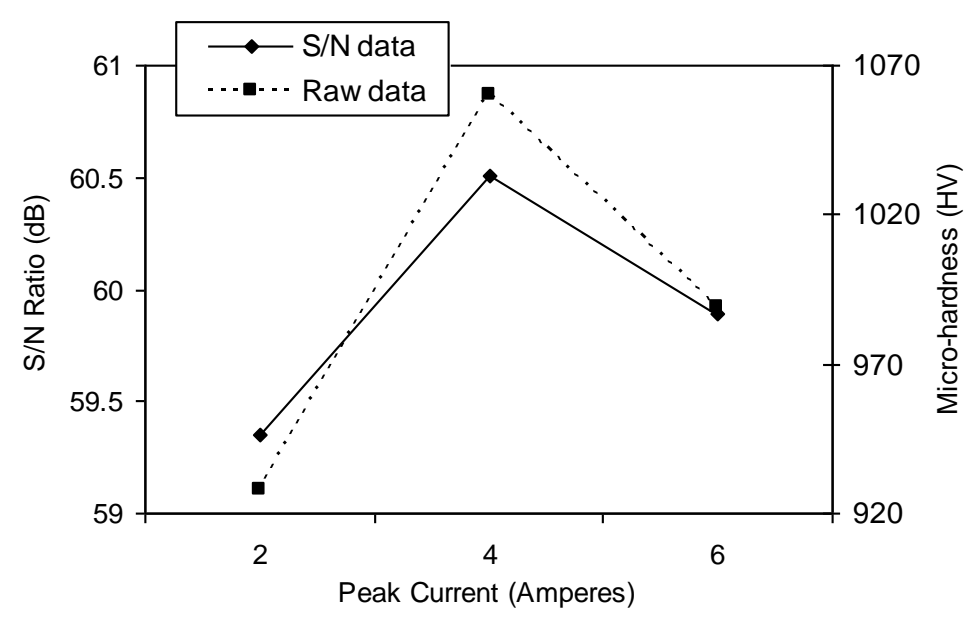

(a)

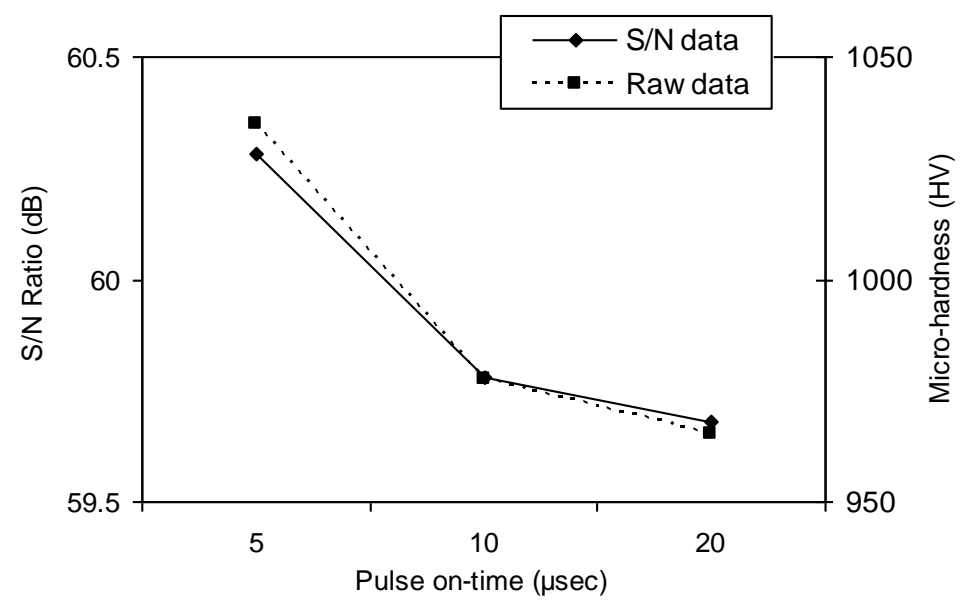

(b)

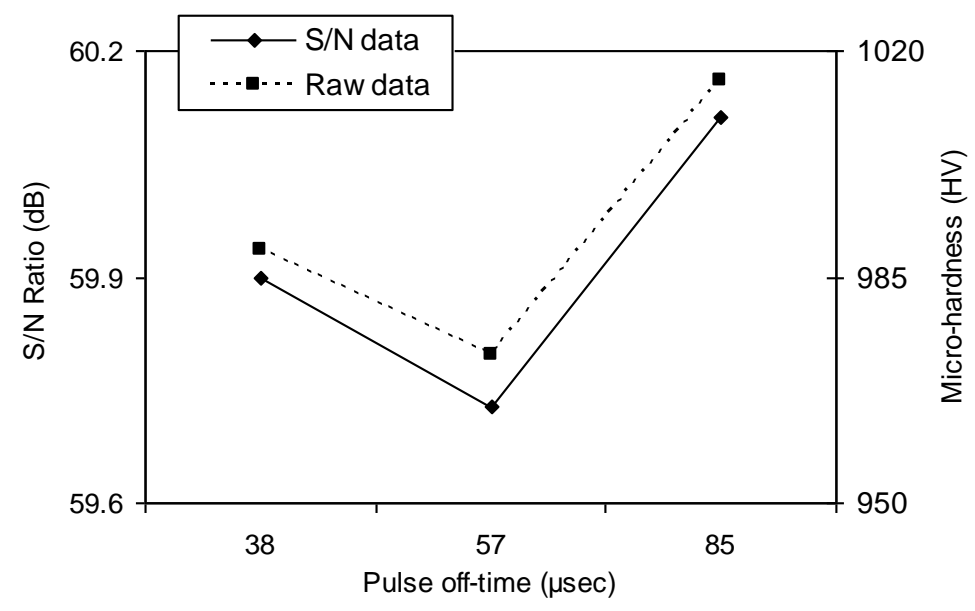

(c)

Figure 6. Effect of (a) Peak current (b) Pulse on-time and (c) Pulse off-time against Micro-hardness and its $\mathrm{S} / \mathrm{N}$ ratio, for $\mathrm{D} 2$ die steel 
Table 6: ANOVA results of $\mathrm{S} / \mathrm{N}$ data for OHNS die steel

\begin{tabular}{lcccccc}
\hline Factor/Source & Sum of squares & DOF & Variance & $\boldsymbol{F}$-ratio & P\% & Remarks \\
\hline Peak Current & 3.8161 & 2 & 1.91081 & 1055.47 & 83.41 & Significant \\
Pulse on time & 0.5320 & 2 & 0.2660 & 147.15 & 11.63 & Significant \\
Pulse off time & 0.2231 & 2 & 0.1116 & 61.72 & 4.88 & Significant \\
Error (pooled) & 0.0036 & 2 & 0.0018 & - & 0.08 & - \\
Total & 4.5748 & 8 & - & - & 100.00 & - \\
\hline
\end{tabular}

$\mathrm{DOF}=$ degrees of freedom, $\mathrm{P} \%=$ percentage contribution

Tabulated value of $F$-ratio at $95 \%$ confidence level $=19$

Table 7. ANOVA results of $\mathrm{S} / \mathrm{N}$ data for $\mathrm{D} 2$ die steel

\begin{tabular}{lllllll}
\hline Factor/Source & Sum of squares & DOF & Variance & $\boldsymbol{F}$-ratio & P\% & Remarks \\
\hline Peak Current & 2.0121 & 2 & 1.0061 & 1176.98 & 70.27 & Significant \\
Pulse on time & 0.6281 & 2 & 0.3141 & 367.40 & 21.93 & Significant \\
Pulse off time & 0.2215 & 2 & 0.1108 & 129.59 & 7.74 & Significant \\
Error (pooled) & 0.0017 & 2 & 0.0009 & - & 0.06 & - \\
Total & 2.8634 & 8 & - & - & 100.00 & - \\
\hline
\end{tabular}

DOF $=$ Degrees of Freedom, P \% = Percentage contribution

Tabulated value of $F$-ratio at $95 \%$ confidence level $=19$

It is observed from the ANOVA table that all three factors have a significant contribution towards the response characteristic of micro-hardness. Peak current emerges as the most important factor. The percentage contribution of pulse off-time has been found to be the smallest of the three and the best micro-hardness has been obtained at the highest setting of this parameter. This means that sufficient idle time is essential for the work surface to cool down and absorb the products of sparking. The percentage error contribution comes out to be only $0.08 \%$ and $0.06 \%$ for OHNS and D2 die steels, respectively, which establishes the adequacy of this orthogonal array in conducting the experimentation and that all the factors have been correctly assigned to its various columns. The factor effects in Figure 5 show that the second level of peak current $\left(A_{2}\right)$, the first level of pulse on-time $\left(B_{1}\right)$, and the third level of pulse off-time $\left(C_{3}\right)$ give the highest values of micro-hardness. Hence, the optimum condition of input process parameters is $A_{2} B_{1} C_{3}$. The theoretical value of $\eta$ under the optimum conditions, denoted by $\eta_{\text {opt }}$, is given by:

$$
\eta_{o p t}=m+\left(m_{A_{2}}-m\right)+\left(m_{B_{1}}-m\right)+\left(m_{C_{3}}-m\right)
$$

where $m$ is the overall mean of the $\mathrm{S} / \mathrm{N}$ data, $m_{A 2}$ is the mean of the $\mathrm{S} / \mathrm{N}$ data for factor $A$ at level 2, $m_{B 1}$ is the mean of the $\mathrm{S} / \mathrm{N}$ data for factor $B$ at level 1, etc. This gives

$$
\eta_{\text {opt }}=60.5266
$$

and the corresponding value of micro-hardness under these optimum conditions, $y_{\text {opt }}$, is

$$
\left(y_{\text {opt }}\right)^{2}=\frac{1}{10-\eta_{\text {opt }} / 10},
$$


or,

$$
y_{o p t}=1062.5 \mathrm{HV}
$$

Since this combination of input process parameters does not exist in the orthogonal array, a set of three confirmation experiments have been conducted with these suggested optimum values. The average micro-hardness in the confirmation experiments was $1049.33 \mathrm{HV}$, which is very close to the theoretical value predicted by the Taguchi analysis. For D2 die steel material, the response of micro-hardness to variation in pulse off-time has been found to be different from that of OHNS work material. OHNS die steel shows an improvement in micro-hardness with an increase in pulse off-time because sufficient de-ionization time results in better quenching effect. However, this material shows a decrease in micro-hardness from level 1 to level 2 and a significant improvement from level 2 to level 3. No apparent reason could be found for this behaviour. For this work material, also, the optimum condition of input process parameters is found to be $\mathrm{A}_{2} \mathrm{~B}_{1} \mathrm{C}_{3}$. The theoretical value of $\eta_{\text {opt }}$ for this optimum condition is given by

$$
\begin{gathered}
\eta_{\text {opt }}=m+\left(m_{A_{2}}-m\right)+\left(m_{B_{1}}-m\right)+\left(m_{C_{3}}-m\right) \\
\eta_{\text {opt }}=61.0719
\end{gathered}
$$

The corresponding value of micro-hardness is

$$
\begin{aligned}
\left(y_{\text {opt }}\right)^{2} & =\frac{1}{10-\eta_{\text {opt }} / 10}, \\
\text { or, } \quad y_{\text {opt }} & =1131.34 \mathrm{HV}
\end{aligned}
$$

Since this combination of input process parameters did not exist in the orthogonal array, a set of three confirmation experiments were conducted. The average value of micro-hardness obtained at this setting of the experiment was $1119 \mathrm{HV}$ which is very close to the theoretical value predicted by the Taguchi analysis. XRD patterns and SEM micrographs of these surfaces are shown in Figures 7-10. The XRD patterns show the formation of manganese carbide $\left(\mathrm{Mn}_{4} \mathrm{C}_{1.06}\right.$ and $\left.\mathrm{Mn}_{7} \mathrm{C}_{3}\right)$ on the surface which is responsible for the much improved hardness. Though manganese is classified as a weak carbide former in steels, machining with manganese powder has resulted in the formation of its carbide on the machined surface.the microstructure shows significant surface changes and a uniform distribution of hard particles which is expected to be very helpful in enhancing the service life of the die cavities. This feature is also desirable from the point of view of retaining lubrication. These surfaces were further subjected to spectrometric analysis for quantitative determination of the elements (Tables 8 and 9) which shows an increase in percentages of manganese as well as carbon. A small amount of copper is also seen in the spectrometric analysis (but not in the XRD pattern due to its very low percentage). As the tool electrode is made up of copper and the machining conditions used for experimentation (low pulse on-time and negative polarity of the tool electrode) favor high tool wear, some of it has alloyed with the workpiece surface. 


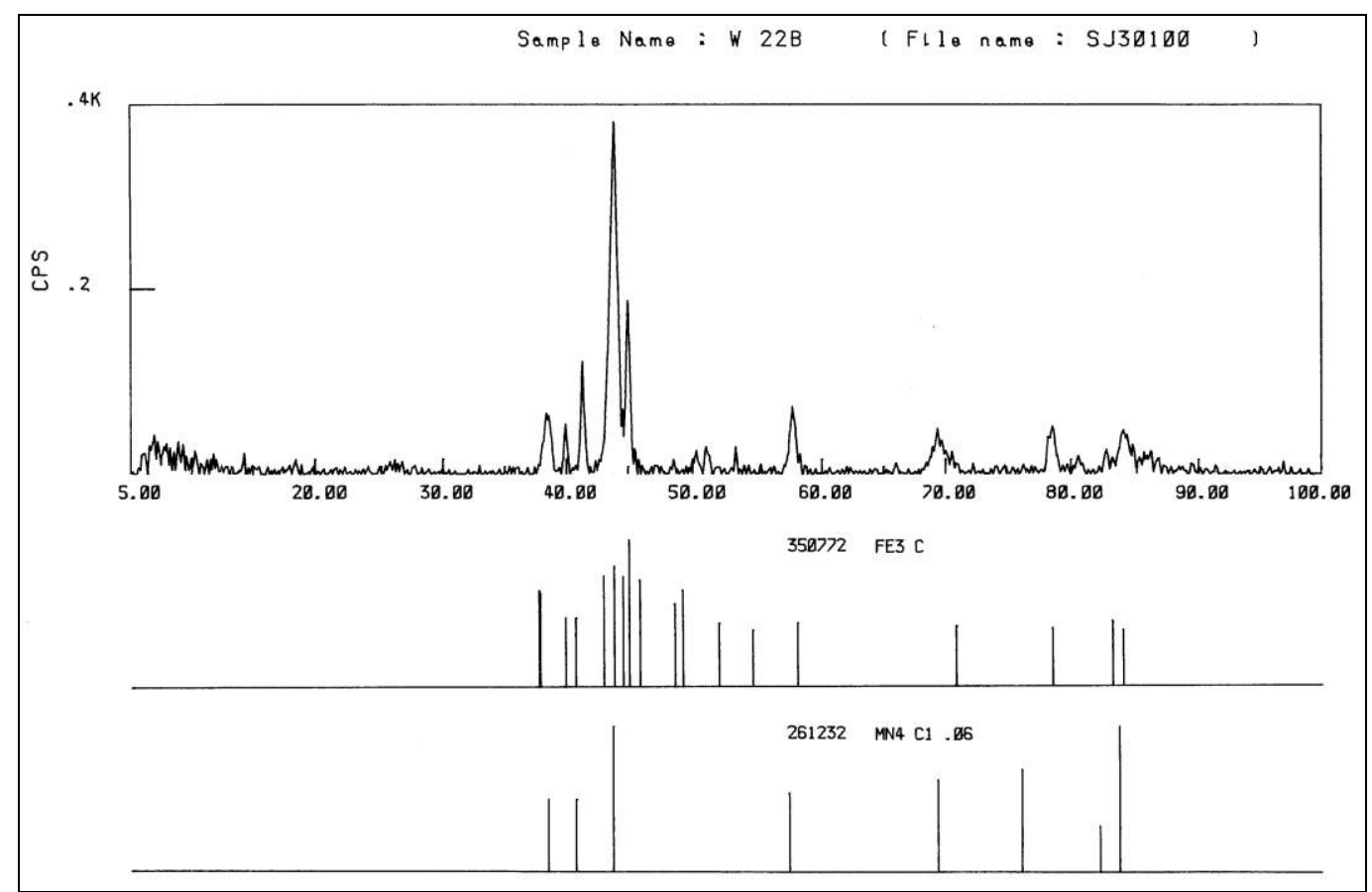

Figure 7. XRD pattern of OHNS die steel after machining with manganese powdermixed dielectric (at $\mathrm{I}_{\mathrm{p}}=4 \mathrm{amp}, \mathrm{P}_{\mathrm{on}}=5 \mu \mathrm{sec}$ and $\mathrm{P}_{\text {off }}=85 \mu \mathrm{sec}$ )

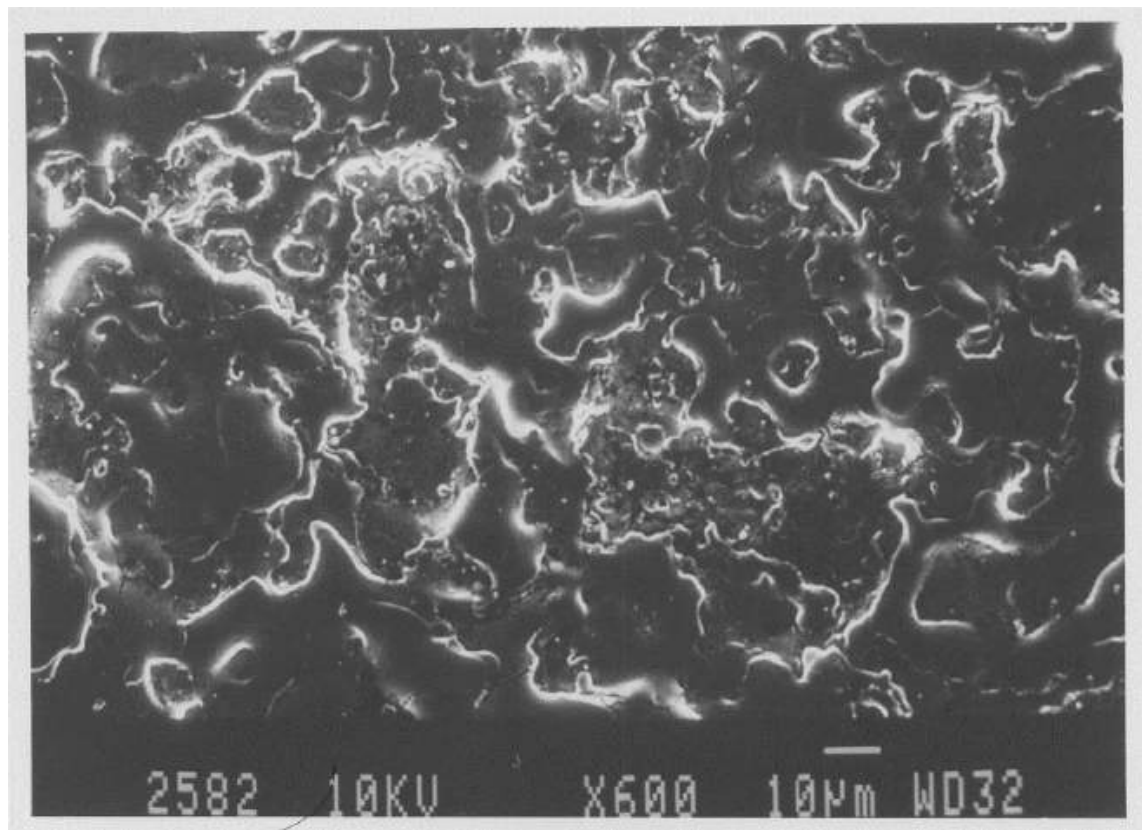

Figure 8. SEM micrograph of OHNS die steel after machining with manganese powdermixed dielectric (at $\mathrm{I}_{\mathrm{p}}=4 \mathrm{amp}, \mathrm{P}_{\text {on }}=5 \mu \mathrm{sec}$ and $\mathrm{P}_{\text {off }}=85 \mu \mathrm{sec}$ ) 


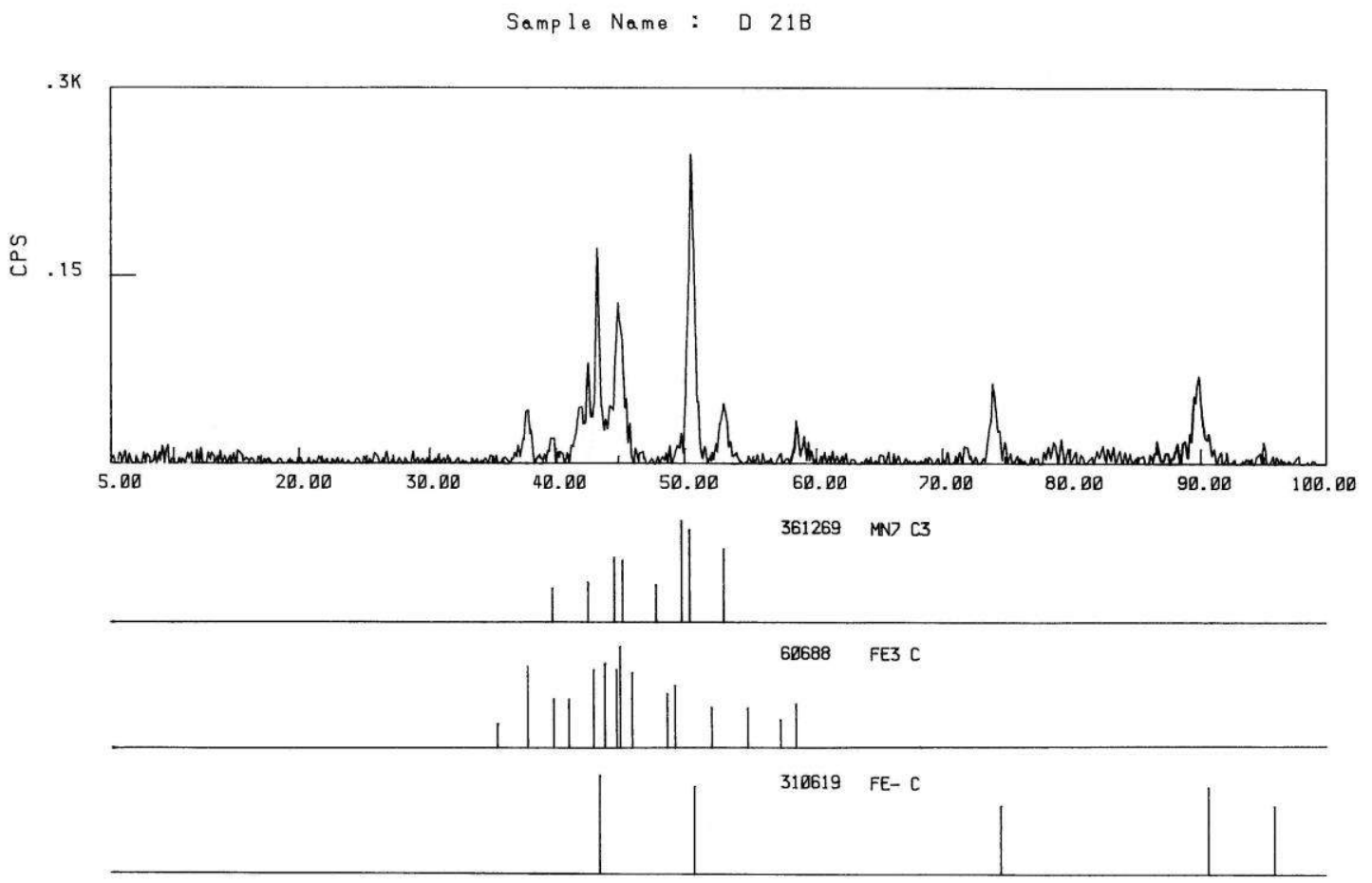

Figure 9. XRD pattern of D2 die steel after machining with manganese powder-mixed dielectric $\left(\right.$ at $\mathrm{I}_{\mathrm{p}}=4 \mathrm{amp}, \mathrm{P}_{\mathrm{on}}=5 \mu \mathrm{sec}$ and $\left.\mathrm{P}_{\text {off }}=85 \mu \mathrm{sec}\right)$

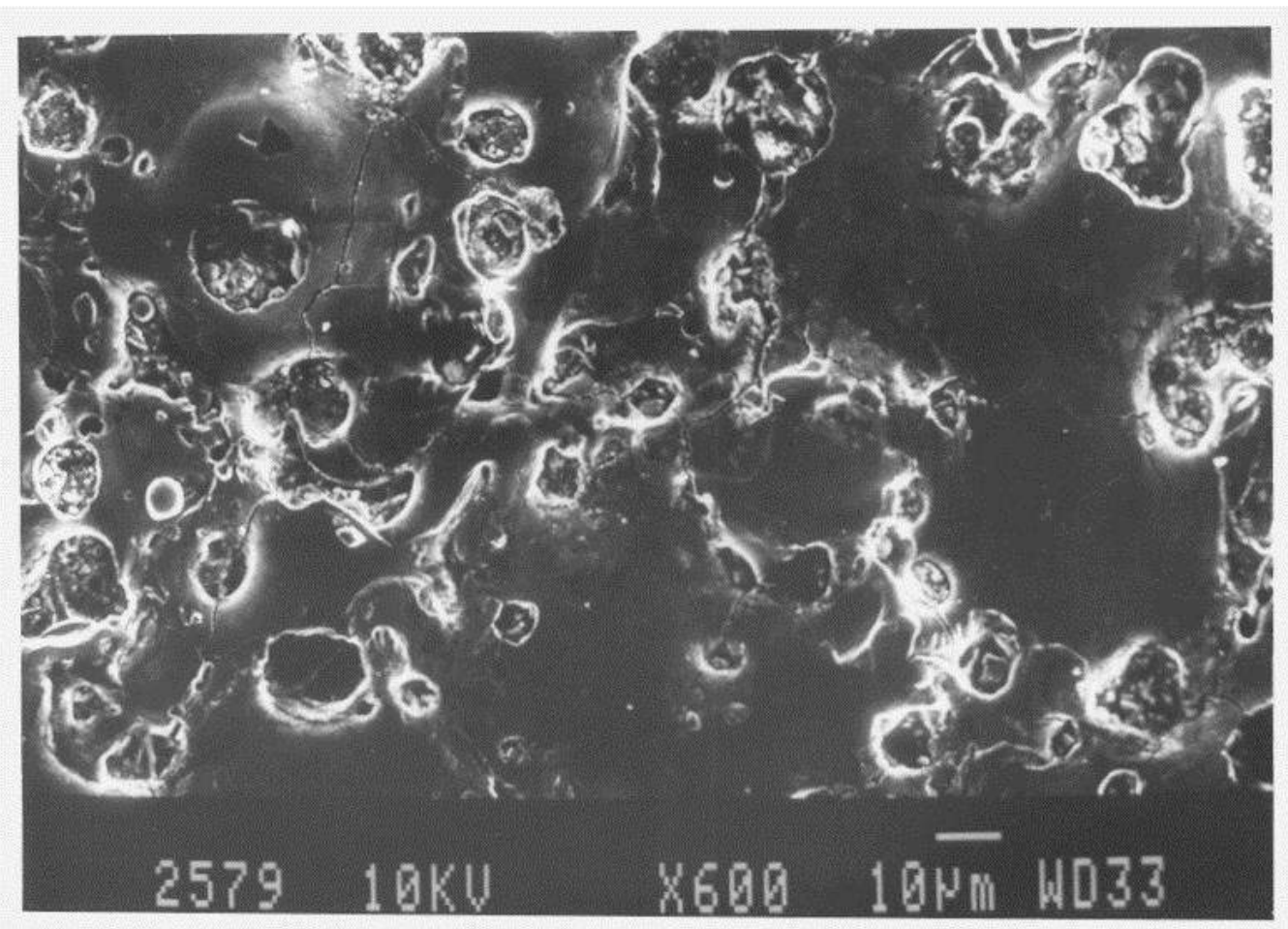

Figure 10. SEM micrograph of D2 die steel after machining with manganese powdermixed dielectric (at $\mathrm{I}_{\mathrm{p}}=4 \mathrm{amp}, \mathrm{P}_{\text {on }}=5 \mu \mathrm{sec}$ and $\mathrm{P}_{\text {off }}=85 \mu \mathrm{sec}$ ) 
Table 8. OHNS chemical composition before and after machining with manganese powder

\begin{tabular}{|l|c|c|c|}
\hline \multirow{2}{*}{ Element } & \multicolumn{3}{|c|}{ Composition (wt. \%) } \\
\cline { 2 - 4 } & Before machining & After machining & Significant changes \\
\hline Carbon & $\mathbf{0 . 8 2}$ & $\mathbf{1 . 0 3}$ & $\mathbf{+ 0 . 2 1}$ \\
\hline Silicon & 0.18 & +0.19 & - \\
\hline Manganese & $\mathbf{0 . 5 2}$ & $\mathbf{0 . 9 5}$ & $\mathbf{+ 0 . 4 3}$ \\
\hline Chromium & $\mathbf{0 . 4 9}$ & $\mathbf{0 . 4 6}$ & - \\
\hline Tungsten & - & - & - \\
\hline Vanadium & 0.19 & 0.19 & - \\
\hline Molybdenum & 0.13 & 0.12 & - \\
\hline Nickel & 0.05 & 0.07 & - \\
\hline Copper & - & $\mathbf{0 . 1 2}$ & $\mathbf{+ 0 . 1 2}$ \\
\hline Iron & Balance & Balance & - \\
\hline
\end{tabular}

Table 9. D2 chemical composition before and after machining with manganese powder

\begin{tabular}{|l|c|c|c|}
\hline \multirow{2}{*}{ Element } & \multicolumn{3}{|c|}{ Composition (wt. \%) } \\
\cline { 2 - 4 } & Before machining & After machining & Significant changes \\
\hline Carbon & $\mathbf{1 . 5 7}$ & $\mathbf{1 . 9 2}$ & $\mathbf{+ 0 . 3 5}$ \\
\hline Silicon & 0.19 & 0.21 & - \\
\hline Manganese & $\mathbf{0 . 0 7}$ & $\mathbf{0 . 6 2}$ & $\mathbf{+ 0 . 5 5}$ \\
\hline Chromium & $\mathbf{1 2 . 3 8}$ & $\mathbf{1 2 . 0 4}$ & $\mathbf{- 0 . 3 4}$ \\
\hline Tungsten & - & - & - \\
\hline Vanadium & 0.96 & 0.94 & - \\
\hline Molybdenum & 0.76 & 0.79 & - \\
\hline Nickel & 0.09 & 0.13 & - \\
\hline Copper & - & $\mathbf{0 . 1 5}$ & $\mathbf{+ 0 . 1 5}$ \\
\hline Iron & Balance & Balance & \\
\hline
\end{tabular}

When machining was carried out without any powder mixed in the dielectric, about $12 \%$ to $15 \%$ increase in micro-hardness was observed. The increase in hardness without powder occurs due to heating and quenching of the machined surface by the flowing dielectric. This effect is more pronounced with an increase in current. The generation of carbon in the dielectric will have more effect on the surface hardness only if machining conditions favoring material transfer are used. The optimum combination of process parameters in these conditions for both the work materials was found to be $\mathrm{A}_{3} \mathrm{~B}_{1} \mathrm{C}_{3}$. Compared to the optimum combination for powder-mixed dielectric, the difference is only in the value of peak current (4 A for machining with powder and $6 \mathrm{~A}$ for machining without powder). The requirement of less peak current in the former case comes from the fact that manganese is already available in the dielectric in powder form whereas in the latter case, more current results in more erosion of the copper tool electrode. Also, a higher peak current means a greater heating and quenching effect on the machined surface. It can also be inferred that for a particular method of machining, the optimum combination of process parameters is independent of the work material and the same set of values will hold good for any work material. 
It has been found that the surface finish deteriorates due to machining in manganese powder-mixed dielectric. Without any powder, the roughness average $\left(R_{a}\right)$ value of $2.46 \mu \mathrm{m}$ was achieved but it varied from $3.31 \mu \mathrm{m}$ to $8.04 \mu \mathrm{m}$ in the presence of manganese powder. It is also observed from Tables 4 and 5 that there is a steady increase in average surface roughness with increase in peak current. It may be inferred that as with normal EDM, the surface roughness with powder-mixed dielectric also depends largely on the peak current only. In confirmation experiments conducted for the best value of micro-hardness, $\mathrm{R}_{\mathrm{a}}$, its value was found to lie between 5 to $6 \mu \mathrm{m}$. But it is important to mention here that in the case of press dies, some deterioration in surface finish may actually be desirable for good lubrication retention and smooth functioning of the dies. A mirror-like surface finish promotes sticky situations between the work piece and die.

\section{CONCLUSIONS}

Experiments were conducted on OHNS and D2 die steels by EDM using machining conditions favouring material transfer from manganese powder suspended in the dielectric medium. The following conclusions may be drawn from this experimental work:

- A significant amount of material transfer can take place from the powder suspended in the dielectric medium to the machined surface, under the appropriate machining conditions, which changes the surface composition and its properties. In this case, it was possible to increase the percentage of manganese in the machined surfaces by about $0.5 \%$.

- At the high temperatures of the plasma channel, the suspended powder can react with carbon from the breakdown of the hydrocarbon dielectric to form carbides, as shown by the presence of manganese carbide $\left(\mathrm{Mn}_{4} \mathrm{C}_{1.06}\right.$ and $\left.\mathrm{Mn}_{7} \mathrm{C}_{3}\right)$ and an increase in the percentage of carbon in the machined surfaces. This resulted in an improvement of more than $70 \%$ in micro-hardness.

- In this experiment, the favorable machining conditions for surface alloying from suspended powders are found to be low peak current (4 amperes), shorter pulse on-time $(5 \mu \mathrm{sec})$, longer pulse off-time $(85 \mu \mathrm{sec})$ and negative polarity of the tool electrode. It appears that long idle times allow the work surface to cool down and absorb the products of sparking.

- All three input process parameters are significant for the response characteristic of micro-hardness, with peak current being the most significant factor: more than $70 \%$ contribution for both work materials. More importantly, it was found that pulse off-time is also significant for the phenomenon of material transfer.

- The best combination of machining parameters for the highest value of microhardness is found to be the same for both the die steels. More experiments need to be conducted with other grades of die steels to establish that the machining parameters are independent of the type of work material.

\section{ACKNOWLEDGMENTS}

The authors are thankful to Dr. M. S. Saini (Director, GNDEC Ludhiana) for providing the lab facilities. 


\section{REFERENCES}

Altan, T., Lilly, B. W., Konig, W., Tonshoff, H. K., Luttervelt, C. A. and Khairy, A. B. (1993) Advanced Techniques for Die and Mould Manufacturing. Annals of CIRP, 42(2): 707-716.

ASM. (1995) ASM Specialty Handbook: Tool Materials. 1 ed. Ohio: ASM International, Materials Park, p. 251.

Aspinwall, D. K., Dewes, R. C., Lee, H. G. and Simao, J. (2003) Electrical Discharge Surface Alloying of $\mathrm{Ti}$ and Fe Workpieces Materials Using Refractory Powder Compact Electrodes and Cu Wire. Annals of CIRP, 52(1): 151-156.

Avner, S.H. (1997) Introduction to Physical Metallurgy 2 ed New Delhi: Tata McGraw Hill.

Bagchi, T. (1993) Taguchi Methods Explained: Practical Steps to Robust Design. NY: Prentice Hall.

Fuller, J. E. (2000) Electrical Discharge Machining, in: ASM Machining Handbook. 16: 557-564.

Furutani, K. and Shimizu, Y. (2003) Experimental Analysis of Deposition Process of Lubricant Surface by EDM With Molybdenum Disulphide Powder Suspended in Working Oil. Proceedings of American Society for Precision Engineering, 30: 547-550.

Furutani, K., Saneto, A., Takezawa, H., Mohri, N. and Miyake, H. (2001) Accretion of Titanium Carbide by Electrical Discharge Machining With Powder Suspended in Working Fluid. Precision Engineering, 25: 138-144.

Galerie, A., Pons, M. and Caillet, M. (1989) Surface Modification Using Lasers and Ion Beams. Material Science and Technology, 5: 806-812.

Ho, K. H. and Newman, S. T. (2003) State of the Art Electrical Discharge Machining. International Journal of Machine Tools \& Manufacture, 43: 1287-1300.

Jain, V. K. (2004) Advanced Machining Processes. New Delhi: Allied Publishers.

Jeswani, M. L. (1981) Effect of Addition of Graphite Powder to Kerosene Used as the Dielectric Fluid in Electrical Discharge Machining. Wear, 70: 133-139.

Kalpakjian, S. and Schmid, S. R. (2001) Manufacturing Engineering \& Technology. $4^{\text {th }}$ Edition. NY: Pearson.

Kumar, S., Singh, R., Singh, T. P. and Sethi, B. L. (2009) Surface Modification by Electrical Discharge Machining: A Review. Journal of Materials Processing Technology, 209(8): 3675-3687.

Kuneida, M., Lauwers, B., Rajurkar, K. P. and Schumacher, B. M. (2005) Advancing EDM Through Fundamental Insight Into the Process. Annals of CIRP, 54(2): 599-622.

Lahiri, B. N., Mukherjee, S. K. and Mullick, B. K. (1981) Loss of Energy in Pyrolysis of Dielectric in EDM Process. Journal of Institution of Engineers(I). 62: 66-69.

Lakhtin, Y. (1983) Engineering Physical Metallurgy. Moscow: Mir Publishers.

Mishra, P. K. (2005) Non Conventional Machining, New Delhi: Narosa.

Montgomery, D. C. (2005) Design and Analysis of Experiments, 5 ed. NY: Wiley.

Phadke, M. S. (1989) Quality Engineering Using Robust Design, AT \& T Bell Laboratories, NJ: Prentice-Hall.

Pollack, H. W. (1988) Materials Science and Metallurgy, 4 ed. Englewood Cliffs, NJ: Prentice-Hall.

Prabhudev, K. H. (2000) Handbook of Heat Treatment of Steels. New Delhi: Tata McGraw Hill. 
Rehbein, W., Schulze, H. P., Mecke, K., Wollenberg, G. and Storr, M. (2004) Influence of Selected Groups of Additives on Breakdown in EDM Sinking. Journal of Materials Processing Technology, 149: 58-64.

Roberts, G. A. and Cary, R. A. (1980) Tool Steels. 4 ed., OH: American Society for Metals.

Roethel, F. and Garbajs, V. (1976) Contributions to the Micro-Analysis of Spark Eroded Surfaces. Annals of the CIRP, 25(1): 135-140.

Ross, Phillip J. (1988) Taguchi Techniques for Quality Engineering. NY: McGraw Hill.

Shankar, N. U. and Krishnan, A. (1979) Polarity Effect in Spark Erosion Machining. Indian Journal of Technology, 17(9): 363-364.

Tzeng, Y. F. and Lee, C. Y. (2001) Effect of Powder Characteristics on Electro Discharge Machining Efficiency. International Journal of Advanced Manufacturing Technology, 17: 586-592.

Uno, Y., Okada, A. and Cetin, S. (2001) Surface Modification of Edmed Surface With Powder Mixed Fluid. Proceedings of the $2^{\text {nd }}$ International Conference on Design and Production of Dies and Molds, pp. 33-45.

Wu, K. L., Yan, B. H., Huang, F. Y. and Chen, S. C. (2005) Improvement of Surface Finish on SKD Steel Using Electro-Discharge Machining With Aluminum and Surfactant Added Dielectric. International Journal of Machine Tools and Manufacture, 45: 1195-1201.

Yan, B. H., Tsai, H. C. and Huang, F. Y. (2005) The Effect in EDM of a Dielectric of a Urea Solution in Water on Modifying the surface of Titanium. International Journal of Machine Tools and Manufacture, 45: 194-200.

Zolotykh, B. N. (1995) Modern Physical Theory of Electric Erosion of Metals-The Basis for Development of New Directions in EDM. Proceedings of International Symposium on Electromachining-XI, pp. 114-116. 